\title{
Deficiencia de hierro, folatos y vitamina B12 en relación a la anemia en niños de escuelas públicas de Tegucigalpa y algunos factores epidemiológicos asociados
}

\author{
María Félix Rivera ${ }^{1}$, Rebeca Rivera², Ivette C. Rivera ${ }^{3}$
}

\section{RESUMEN}

Objetivo: determinar la implicación que tiene la presencia de anemia en niños escolares tanto hierro así como la deficiencia de acido fólico y vitamina B12.

Metodología: es un estudio tipo descriptivo, transversal, diseño por conglomerado, se seleccionaron todos los niños de primer grado de ocho escuelas primarias públicas de Tegucigalpa, muestreo por conglomerado para una muestra de 450 niños. A todos se les realizó una encuesta completa con datos personales, alimentación, talla, peso. Se le extrajeron $5 \mathrm{ml}$ sangre mediante punción venosa cubital, en horario matutino, se utilizó un contador hematológico automatizado ABX Pentra 120; los niveles de ferritina, ácido fólico y vitamina B12. Ferritina, vitamina B12 y ácido fólico, se determinaron mediante enzimoinmunoanálisis de micropartículas utilizando el sistema automatizado AxSYM. Como criterios de anemia se consideró $\mathrm{Hb}<11.5 \mathrm{~g} / \mathrm{dl}$. La deficiencia de Ferritina se consideró < 15 ug/l, la de vitamina B12 < $203 \mathrm{pg} / \mathrm{ml}$ y la de folatos $<4 \mathrm{ng} / \mathrm{ml}$. El nivel socioeconómico (NSE) se determinó mediante el Método de Graffar Modificado, el crecimiento se clasificó según parámetros propuestos por el INCAP. Se evaluó el consumo de alimentos a través de un recordatorio de 24 horas. Los resultados fueron analizados con estadística descriptiva, se utilizó paquete estadístico EPIINFO versión 3.5.1. Para Windows.

Resultados: el promedio de edad fue de 6.7 años y el $46.4 \%$ pertenecían al sexo femenino y $53.6 \%$ al masculino, la prevalencia de anemia fue de $8.9 \%$ (IC al 95\%: 6.5\% a 12.1\%). El 9.2\% (IC al 95\%: 6.8\% a 12.3\%) tenían deficiencia de vitamina

\footnotetext{
${ }^{1}$ Universidad Nacional Autónoma de Honduras. Facultad de Ciencias Médicas. Departamento de Fisiología. Médico Asistencial del Centro Odontopediátrico y Detección de Otras Patologías (CODOPA). Región Sanitaria Metropolitana. Secretaría de Salud.

${ }^{2}$ Universidad Nacional Autónoma de Honduras. Facultad de Ciencias. Escuela de Microbiología.

${ }^{3}$ Universidad Nacional Autónoma de Honduras. Facultad de Ciencias Sociales. Escuela de Psicología. PsicólogaAsistencial del Centro Odontopediátrico y Detección de Otras Patologías (CODOPA) de la Región Sanitaria Metropolitana. Secretaría de Salud.
} 
B12 y el 6.4\% (IC al 95\%: 4.42\% a 9.2\%) tenían niveles bajos de ferritina, y ninguno tenía deficiencia de ácido fólico. Uno de cada cien tenían deficiencia de ferritina acompañado de deficiencia de vitamina B12, cinco de cada cien tenía solo deficiencia de ferritina y ocho de cada cien tenía únicamente deficiencia de vitamina B12 y el $14.3 \%$ de los escolares tenían al menos un tipo de deficiencia de vitamina B12 o/y de Ferritina. El promedio de vitamina B12 encontrado fue de $375.97 \mathrm{pg} / \mathrm{ml}$ (163.7 $\pm 1 D E)$, de ácido fólico $12.96 \mathrm{ng} / \mathrm{ml}(2.02 \pm 1 \mathrm{DE})$ y de ferritina $34.73 \mathrm{ng} / \mathrm{ml}$ $(17.55 \pm 1 \mathrm{DE})$.

Se encontró una relación directamente significativa en los escolares que habían consumido cereal, frijoles y niveles de ferritina altos.. El nivel alto de ácido fólico se relacionó con el consumo de leche, cereal, frutas y verduras, el alto nivel de vitamina B12 se asoció al consumo de leche y ambas diferencias mostraron ser significativas Los niveles de vitamina B12 eran más altos en los niños que habían consumido carne sin tener relevancia estadística. Se encontró que a menor nivel socioeconómico menor nivel de vitamina B12, ácido fólico y ferritina, únicamente en este último los niveles no fueron significativos, al igual entre el nivel socioeconómico, anemia y estado nutricional no hubo diferencias realmente contrastantes.

Conclusiones: los resultados de esta investigación se prestan para la toma de decisiones a nivel gubernamental a través de políticas nutricionales certeras dando solución para erradicar problemas nutricionales que son completamente prevenibles.

\section{Palabras claves: Anemia, deficiencia de vitamina B12, deficiencia de ferritina, deficiencia de ácido fólico, escolar.}

\section{ABSTRACT}

Objective: To determine the implication of anemia, caused by deficiency of iron, folates and $B_{12}$ vitamin, on school children.

Methodology: It is a descriptive transversal study. The sample consisted of 450, first grade school children; cluster sampling distributed over 8 public schools at Tegucigalpa. Each child was identified by name, age, sex, school name, food intake, weight and height; the average age was 6.7 years old, $46.4 \%$ female and $53.6 \%$ males. Five $\mathrm{ml}$ of blood was drawn for each child. The automatized method ABX pentra 120 was used for hemoglobin and hematocrit measurement. The automatized Abbott, AXSYM enzyme immunoassay system, was used for serum determination of ferritin, $B_{12}$ vitamin and folates. The World Health Organization's 
deficiencies criteria parameters were considered: $\mathrm{Hb}<11.5 \mathrm{~g} / \mathrm{dl}$, ferritin $<15 \mathrm{ug} / \mathrm{l}$, $B_{12}$ vitamin $<203 \mathrm{pg} / \mathrm{ml}$ and folates $<4 \mathrm{ng} / \mathrm{ml}$. The social-economic level was determined by the Graffar modified method, the child growth indicator was classified according INCAP parameters. The food intake was evaluated through 24 hours follow up. Data were analyzed using EPI-INFO version 3.5.1 Results: The prevalence of anemia (hemoglobin $<11.5 \mathrm{~g} / \mathrm{dl}$ ) was $8.9 \%$ (IC $95 \%=6.5 \%$ to $12.1 \%$. Results showed that $9.2 \%$ (IC al 95\%: 6.8\% a 12.3\%) of the children were deficient on $B_{12}$ vitamin; and 6.4\% (IC al 95\%: 4.42\% a 9.2\%) were deficient on ferritin, and none was deficient on folates. One of 100 children were deficient on ferritin and on B12 vitamin; $5 \%$ were deficient only on ferritin and $8 \%$ were deficient only on $B_{12}$ vitamin; and $14.3 \%$ of the school children had un type of deficiency, $\mathrm{B}_{12}$ vitamin or

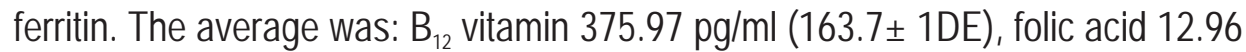
$\mathrm{ng} / \mathrm{ml}(2.02 \pm 1 \mathrm{DE})$ and ferritin $34.73 \mathrm{ng} / \mathrm{ml}(17.55 \pm 1 \mathrm{DE})$.

The results showed a significant and direct relation between high concentration of ferritin and the consumption of cereal and beans. The high level of folates was related with the consumption of milk, cereals, fruits and vegetables. High levels of vitamin $B_{12}$ were related with milk intake. Low economic level was related with low levels of $B_{12}$ vitamin, folates and ferritin.

Conclusions: The results of this study are important for decision makers at national level for developing effective nutritional control programmes. The anemia on school children it is an important public health problem that needs prevention and intervention.

Key words: Anemia, $B_{12}$ vitamin deficiency, ferritin deficiency, folic acid deficiency, school children. 


\section{INTRODUCCIÓN}

La anemia es una enfermedad prevalente a nivel mundial, y entre sus causas la más frecuente es por deficiencia de hierro, es un problema de salud pública en países en vías de desarrollo y en industrializados ${ }^{1}$. Sin embargo actualmente se está renovando la importancia que podría tener en la causalidad de la anemia la deficiencia tanto de ácido fólico o folatos como de cobalamina o vitamina B12 los cuales están relacionados no únicamente con anemia sino tienen que ver con el aparecimiento de enfermedades tales como malformaciones congénitas, algunos tipos de cáncer, riesgo cardiovascular y alteraciones cognitivas. ${ }^{2}$ La vitamina B12 es sintetizada por microorganismos y se encuentra en las carnes, pescados y productos lácteos, no se encuentra ni en frutas ni en vegetales, pero tiene que pasar mucho tiempo de dieta deficiente en vitamina B12 para que se presenten manifestaciones, por lo tanto; la ingesta inadecuada es la principal causa de su carencia y el alto precio de los productos que la contienen hace que tenga una relación con el nivel socioeconómico e ingreso de la población ${ }^{2}$.

Últimamente las deficiencias de ácido fólico y vitamina B12 han emergido como un problema importante en países en desarrollo, así en Costa Rica se observó una prevalencia de deficiencia de ácido fólico en menores de 7 años de un $11.4 \%$ y solo un $2.3 \%$ en grado severo ${ }^{3}$. En Guatemala, se realizó un estudio a niños de 8 y 12 años de edad, en el cual los resultados arrojaron niveles bajos de de vitamina B12 en un $11 \%$ y niveles marginales en un $22 \%$, con respecto a folatos los porcentajes fueron 0 y $1 \%$ respectivamente ${ }^{4}$.

En cambio los estudios realizados en adolescentes, se encontró una significativa asociación bajos niveles de cobalamina, con puntajes disminuidos de inteligencia fluida, habilidad espacial y memoria a corto plazo. Los mecanismos por los que la deficiencia de cobalamina causa disfunción cognitiva aún quedan por aclarar, ${ }^{5,6}$. En Honduras, desde hace 5 décadas la anemia por deficiencia de hierro fue reconocida como un problema de salud pública y con el apoyo de algunas instituciones se han fortificado algunos alimentos. En 1995, un estudio realizado en escolares de primer grado de escuelas públicas de Tegucigalpa se encontró una prevalencia de anemia del $29.4 \%{ }^{7}$. En 1999, se encontró que el 30\% de los niños menores de 6 años tenían anemia sin precisar cuál era la causa ${ }^{8}$.

El interés de esta investigación fue determinar la implicación que tiene en la presencia de anemia en niños de escuelas públicas de Tegucigalpa tanto la deficiencia de ferritina como de ácido fólico y vitamina B12 y relacionarlo con algunos aspectos epidemiológicos. 


\section{METODOLOGÍA}

El estudio se inició en el 2009 y concluyó en el año 2010. El diseño seleccionado fue de tipo descriptivo transversal. El universo fueron todos los escolares matriculados en primer grado de ocho escuelas públicas de Tegucigalpa MDC del año 2009. Se calculó una muestra de 450 escolares, considerando los siguientes criterios; un nivel de confianza de $95 \%$ ( $Z=1.96$ ); un nivel de precisión de $5 \%$ y una prevalencia estimada de $50 \%$ dado que no contamos con datos disponibles de deficiencia de vitamina B12; ácido fólico y ferritina en población escolar en nuestro país.

El muestreo fue por conglomerado, para la selección de los escolares se dividió el área geográfica de Tegucigalpa en 8 zonas y de cada una de ellas se seleccionó una escuela por sector tomando en cuenta el criterio de accesibilidad vehicular (se seleccionó la escuela más viable del sector, especialmente en lo referente a vías de comunicación). Se les solicitó su consentimiento informado y firmado a los padres de los niños que asistían a primer grado, luego se incluyeron únicamente los escolares que tuvieron el consentimiento de los padres firmado.

A cada escolar se le identificó por su nombre, edad, sexo y el nombre de la escuela. Se le tomaron datos personales, socioeconómicos, peso y talla. Se le extrajeron 5 $\mathrm{ml}$ sangre mediante punción venosa cubital con jeringas y agujas en horario matutino, $2 \mathrm{ml}$ se depositaron en tubos con EDTA para efectuar los hemogramas, utilizando un contador hematológico automatizado ABX Pentra 120; los $3 \mathrm{ml}$ restantes se centrifugaron para obtener suero el cual se congeló en dos alicuotas para efectuar un estudio de niveles de ferritina, ácido fólico y vitamina B12; los cuales se determinaron mediante el enzimoinmunoanálisis de micropartículas utilizando el sistema automatizado AxSYM. La anemia se clasificó según el nivel de la hemoglobina y de acuerdo a la edad. Niños de 6 a 9 años con hemoglobina por debajo de $11.5 \mathrm{~g} / \mathrm{dl}$ fueron clasificados como anémicos.

Como criterios de anemia se consideró los puntos de corte para niños escolares establecidos por la organización Mundial para la salud y el grupo consultivo internacional sobre anemia nutricional: $\mathrm{Hb}<11.5 \mathrm{~g} / \mathrm{dl}$, en el grupo etario de 5 a 11 años y para la evaluación de la gravedad de anemia se tomó como criterio de anemia ligera valores de 10 a $11.9 \mathrm{~g} / \mathrm{dl}$, moderada entre 9.9 y $7.0 \mathrm{~g} / \mathrm{dl}$ y severa menor de $7.0 \mathrm{~g} / \mathrm{dl}^{9}$. La deficiencia de Ferritina se consideró a niveles menores de < $15 \mathrm{ug} / \mathrm{I}^{10}$, deficiencia de vitamina B12 a niveles menores de $203 \mathrm{pg} / \mathrm{ml}$ y la deficiencia de folatos a niveles menores de $4 \mathrm{ng} / \mathrm{ml}^{11}$. El nivel socioeconómico (NSE) se determinó mediante el Método de Graffar Modificado, que incluye escolaridad y ocupación del jefe del hogar y vivienda especialmente adaptada para 
estrato socioeconómico urbano. La escala permitió categorizar a la muestra en 6 estratos: 1= NSE alto-alto; 2= NSE medio-alto; 3= NSE medio; 4= NSE medio-bajo; $5=$ NSE bajo-bajo y $6=$ Miseria. En el presente estudio se categorizó a la muestra en tres estratos: NSE alto (1+2), NSE medio (3+4) y NSE bajo $(5+6)^{12}$. Para clasificar el crecimiento se utilizaron parámetros propuestos por el Instituto de Nutrición de Centro América y Panamá (INCAP), aplicables a niños mayores de cinco años, estos parámetros son aceptados por el Centro Nacional de Estadísticas para la Salud de los Estados Unidos de América (NCHS) y la Organización Mundial para la Salud (OMS). De acuerdo a dichos parámetros se ha hecho la siguiente clasificación; crecimiento normal, si la talla esta por arriba de -2 desviaciones estándar (DE); retardo del crecimiento moderado, cuando la talla se encuentra entre -2 y -2.9 DE y retardo del crecimiento severo, si la talla se ubica por debajo de -3 $D E^{13}$.

Se evaluaron también consumo de alimentos como ser: carnes, vegetales, leche, cereal, frutas, arroz y frijoles a través de un recordatorio de 24 horas del día anterior a la entrevista.

Los resultados fueron analizados con la estadística descriptiva, reportando valores de concentración como el promedio, desviaciones estándar (DE), porcentajes e intervalos de confianza del 95\%. Para observar diferencia se utilizó la prueba T o F según fue necesario y el nivel de significancia para una $p<$ de 0.05 . Cuando la frecuencia de una celda de la tabla de $2 \times 2$ fue menor de 5 se utilizó la prueba exacta de Fisher. Para el procesamiento de la información se utilizó paquete estadístico EPI-INFO versión 3.5.1. Para Windows (Center of Disease control and prevention, Atlanta, Georgia, USA).

\section{RESULTADOS}

El promedio de edad fue de 6.7 años $\pm 1.041 \mathrm{DE}$, y el $46.4 \%$ pertenecían al sexo femenino y $53.6 \%$ al masculino, la prevalencia de anemia fue de $8.9 \%$ (IC al 95\%: 6.5\% a 12.1\%). El 9.2\% (IC al 95\%: 6.8\% a 12.3\%) tenían deficiencia de vitamina B12 y el 6.4\% (IC al 95\%: 4.42\% a 9.2\%) tenían niveles bajos de ferritina, y ninguno tenía deficiencia de ácido fólico.

Uno de cada cien tenían deficiencia de ferritina acompañado de deficiencia de vitamina B12, cinco de cada cien tenía solo deficiencia de ferritina y ocho de cada cien tenía únicamente deficiencia de vitamina B12 y en resumen el $14.3 \%$ de los escolares tenían algún tipo de deficiencia de vitamina B12 o/y de Ferritina. En cuanto a los niveles, el promedio de vitamina B12 encontrado en los escolares 
estudiados fue de $375.97 \mathrm{pg} / \mathrm{ml}$ (163.7士 1DE), de ácido fólico $12.96 \mathrm{ng} / \mathrm{ml}(2.02 \pm$ $1 \mathrm{DE})$ y de ferritina $34.73 \mathrm{ng} / \mathrm{ml}(17.55 \pm 1 \mathrm{DE})$.

Cuadro No. 1. Presencia de anemia en relación a la deficiencia de Ferritina, Ácido Fólico y Vitamina B12.

Estudio en escolares de Escuelas Públicas de Tegucigalpa, Honduras. Año 2009-2010

\begin{tabular}{l|c|c|c|c|}
\hline \multirow{2}{*}{} & \multicolumn{3}{|c|}{ Anémicos } & \multicolumn{2}{c|}{ No Anémicos } \\
\cline { 2 - 5 } & No. & $\%$ & No. & $\%$ \\
\hline Deficiencia solo de ferritina & 3 & 8.3 & 21 & 5.3 \\
\hline $\begin{array}{l}\text { Deficiencia solo de vitamina B12 } \\
\text { Deficiencia de vitamina B12 y ferrtitina }\end{array}$ & 2 & 5.5 & 34 & 8.5 \\
$\begin{array}{l}\text { Niveles normales de vitamina B12 y } \\
\text { ferritina }\end{array}$ & 29 & 8.5 & 3 & 0.8 \\
\hline TOTAL & 36 & 100.0 & 340 & 85.4 \\
\hline
\end{tabular}

El $8.3 \%$ de los anémicos tenían deficiencia de ferritina, un 5.5\% deficiencia de vitamina B12, y un 5.5\% deficiencia de ambos, y al compararlos con escolares que no tenían anemia presentaban prácticamente el mismo porcentaje de deficiencia de ferritina (5.3\%) y un 8.5\% deficiencia de vitamina B12 mayor que en el grupo de escolares anémicos y a menos de un uno porciento los que tenían deficiencia de los dos en el grupo de escolares no anémicos como se observa en el cuadro No.1 Al comparar todos los que tenían al menos una deficiencia con los que tenían niveles normales de vitamina B12 y ferritina y la presencia de anemia no se encontraron diferencias estadísticamente significativas $p=0.58$

Cuadro No. 2. Relación entre los niveles de Ferritina y Acido fólico y Vitamina B12 y el nivel socioeconómico.

Estudio en escolares de Escuelas Públicas de Tegucigalpa, Honduras. Año 2009-2010

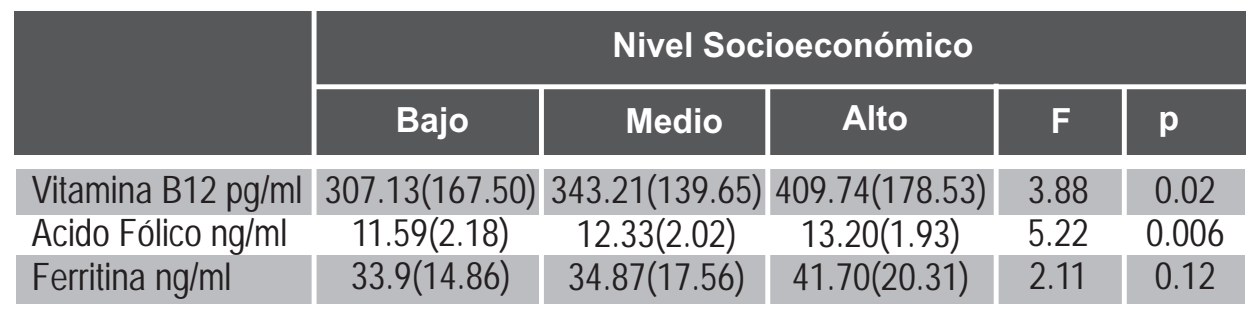

1Desviación Estándar entre paréntesis. $p<$ de 0.05 es significativo 
Al evaluar el nivel socioeconómico (NSE), encontramos que los escolares estudiados el $22.9 \%$ pertenecía al nivel alto, el $59.0 \%$ al nivel medio y $18.1 \%$ al nivel bajo y al relacionarlo con la presencia de anemia en los escolares y nivel NSE no se encontraron diferencias significativa, sin embargo al asociar los promedios de los niveles de ferritina, ácido fólico y vitamina B12 y NSE, se encontró que a mayor nivel NSE, mayores niveles de ferritina, ácido fólico y vitamina B12 y viceversa, cuyas diferencias solo fueron estadísticamente significativas con vitamina B12 y ácido fólico no así con ferritina las diferencias no fueron estadísticamente significativas como se observa en el cuadro No.2

Cuadro No. 3. Consumo de alimentos según recordatorio de 24 horas en comparación con el promedio de Ferritina, Ácido Fólico y Vitamina B12.

Estudio en escolares de Escuelas Públicas de Tegucigalpa, Honduras. Año 20092010

\begin{tabular}{|c|c|c|c|c|c|c|c|c|c|}
\hline \multicolumn{10}{|c|}{ Niveles } \\
\hline & \multicolumn{3}{|c|}{ Ferritina ng/ml } & \multicolumn{3}{|c|}{ Ácido Fólico ng/ml } & \multicolumn{3}{|c|}{ Vitamina B12 pg/ml } \\
\hline & Promedio & $\mathbf{t}$ & p & Promedio & $\mathbf{t}$ & $\mathbf{p}$ & Promedio & $\mathbf{t}$ & $p$ \\
\hline LECHE & & & & & & & & & \\
\hline $\begin{array}{l}\mathrm{Si} \\
\text { No }\end{array}$ & $\begin{array}{l}35.6(15.7) \\
37.6(18.7)\end{array}$ & 0.57 & 0.56 & $\begin{array}{l}12.8(1.9) \\
12.0(1.9)\end{array}$ & 2.77 & 0.00 & $\begin{array}{l}365.0(155.4) \\
315.9(129.8)\end{array}$ & 2.63 & 0.00 \\
\hline ARROZ & & & & & & & & & \\
\hline $\begin{array}{l}\mathrm{Si} \\
\text { No }\end{array}$ & $\begin{array}{l}36.1(17.7) \\
36.9(15.1)\end{array}$ & 0.25 & 0.80 & $\begin{array}{l}12.4(2.0) \\
12.4(2.0)\end{array}$ & 0.05 & 0.79 & $\begin{array}{l}368.7(153.1) \\
335.2(143.3)\end{array}$ & 1.28 & 0.19 \\
\hline CARNE & & & & & & & & & \\
\hline $\begin{array}{l}\mathrm{Si} \\
\text { No }\end{array}$ & $\begin{array}{l}36.8(17.7) \\
35.3(16.3)\end{array}$ & 0.56 & 0.57 & $\begin{array}{l}12.5(1.9) \\
12.4(2.1)\end{array}$ & 0.25 & 0.79 & $\begin{array}{l}347.8(154.5) \\
331.9(128.9)\end{array}$ & 0.71 & 0.47 \\
\hline CEREAL & & & & & & & & & \\
\hline $\begin{array}{l}\mathrm{Si} \\
\text { No }\end{array}$ & $\begin{array}{l}40.5(19.7) \\
34.3(15.6)\end{array}$ & 2.3 & 0.02 & $\begin{array}{l}12.9(1.9) \\
12.2(2.0)\end{array}$ & 2.28 & 0.02 & $\begin{array}{l}369.7(158.1) \\
329.2(138.9)\end{array}$ & 1.78 & 0.07 \\
\hline FRIJOLES & & & & & & & & & \\
\hline $\begin{array}{l}\mathrm{Si} \\
\text { No }\end{array}$ & $\begin{array}{l}40.5(19.7) \\
34.3(15.6)\end{array}$ & 2.3 & 0.02 & $\begin{array}{l}12.5(2.0) \\
12.3(2.0)\end{array}$ & 0.64 & 0.52 & $\begin{array}{l}330.7(128.9) \\
363.6(170.9)\end{array}$ & 1.49 & 0.13 \\
\hline FRUTA & & & & & & & & & \\
\hline $\begin{array}{l}\mathrm{Si} \\
\text { No }\end{array}$ & $\begin{array}{l}37.4(17.6) \\
34.9(16.8)\end{array}$ & 0.96 & 0.33 & $\begin{array}{l}12.8(1.7) \\
12.0(2.3)\end{array}$ & 0.54 & 0.01 & $\begin{array}{l}349.2(143.1) \\
334.3(143.1)\end{array}$ & 0.77 & 0.43 \\
\hline VERDURAS & & & & & & & & & \\
\hline $\begin{array}{l}\mathrm{Si} \\
\text { No }\end{array}$ & $\begin{array}{l}37.9(17.8) \\
34.9(16.8)\end{array}$ & 1.16 & 0.24 & $\begin{array}{l}12.9(1.8) \\
12.1(2.2)\end{array}$ & 2.83 & 0.00 & $\begin{array}{l}349.0(146.1) \\
335.2(146.2)\end{array}$ & 0.64 & 0.51 \\
\hline
\end{tabular}

*Entre paréntesis se observa la desviación estándar, $p<$ de 0.05 es significativo 
Debido a la importancia que tiene la alimentación en la aparición de estas deficiencias se hizo un análisis de los alimentos consumidos de alto valor nutritivo, a través de un recordatorio de 24 horas; encontrando una relación directa en los escolares que habían consumido cereal y frijoles y mayor nivel de ferritina a diferencias de los que no habían consumido estos alimentos y las diferencias fueron estadísticamente significativas.

En cuanto al ácido fólico encontramos que los que reportaron haber consumido leche, cereal, frutas y verduras tenían un mayor nivel de ácido fólico que no lo que no habían consumido estos alimentos y las diferencias fueron estadísticamente significativas, en cuanto a vitamina B12 los que reportaron haber consumido leche eran los únicos que las diferencias eran estadísticamente significativas con los que no habían consumido leche. En los niños que habían consumido carne los niveles de vitamina B12 eran más altos a diferencia de quienes no la habían consumido, sin ser significativo, como se observa en el cuadro No.3

En cuanto al estado nutricional, el $5.7 \%$ tenían retardo moderado del crecimiento y un 3.3\% retardo severo del crecimiento y el resto talla adecuada para su edad. E $11.1 \%$ de la población estudiada tenían retardo moderado del crecimiento y un $5.6 \%$ retardo severo del crecimiento y ambos grupos mostraron deficiencia de cobalamina, a diferencia de los que tenían niveles dentro de rangos normales de vitamina B12 el porcentaje fue menor: el 4.9\% tenían retardo moderado del crecimiento y $2.9 \%$ retardo severo. Las diferencias no fueron estadísticamente significativas $(p=0.21)$.

De los niños estudiados con niveles de ferritina deficientes el $11.1 \%$ tenían retardo moderado del crecimiento y el $11.1 \%$ retardo severo del crecimiento y de los que tenían niveles normales de ferritina el porcentaje era menor: con retardo moderado del crecimiento un $5.4 \%$ y un $2.7 \%$ retardo severo del crecimiento. Las diferencias no fueron estadísticamente significativas $(\mathrm{p}=0.19)$.

\section{DISCUSIÓN}

Los problemas de anemia por deficiencia de hierro se ha venido manejando desde hace muchas décadas, en este estudio se encontró que de los que tenían anemia sólo un 8.3\% tenían deficiencia de ferritina, con la salvedad de que no se realizó otra prueba especialmente para descartar infecciones como ser Proteína C Reactiva (PCR) y se encontró que ocho de cada diez anémicos tenían ferritina y vitamina B12 normales, en vista de que no tenemos otra prueba para confirmar la deficiencia de hierro podría tratarse de deficiencia de hierro, ya que es la más frecuente. 
En una comunidad de Ecuador Quizhpe y col, encontraron una prevalencia de anemia de $16.6 \%$ en escolares estudiados de los cuales el 75.5\% tenían anemia por deficiencia de hierro. ${ }^{14}$ En nuestro estudio encontramos que aproximadamente uno de cada diez niños tenía deficiencia de vitamina B12 y ninguno de ácido fólico, en comunidades rurales de México se encontró una alta deficiencia de vitamina B12 y no así de folatos como en nuestro estudio ${ }^{15}$. En Guatemala, en un estudio con escolares entre 8 y 12 años de edad, se encontraron niveles bajos de vitamina B12 en un $11 \%$ levemente superior al encontrado en nuestro estudio e igualmente que en nuestro estudio no encontraron deficiencia de ácido folico ${ }^{16}$.

En Chile, investigaciones mostraron también una baja deficiencia de ácido fólico en escolares $(1.2 \%)^{17}$. Por otro lado, estudios en escolares realizados en Venezuela, muestran un alto porcentaje de deficiencia de vitamina B12 (27.5\%) y de ácido fólico (31.5\%), mucho más alto de lo encontrado en nuestro estudio ${ }^{18}$. Muy parecido, en la India, en el 2002, se evaluaron todos los ingresos con anemia megaloblastica desde la edad de 6 meses a 12 años y encontraron una prevalencia de déficit de ácido fólico en un $50 \%$ de los casos, y déficit de vitamina B12 en un $62 \%$ y mixta en un $30 \%{ }^{19}$.

En nuestra investigación se encontró escasa variabilidad entre las deficiencias vitamina B12, ferritina y ácido fólico y el nivel socioeconómico igual con la presencia de anemia y desnutrición en los escolares sin presentar significancia estadística. Pero si, los resultados en este estudio con respecto a los alimentos estudiados a través de un recordatorio de 24 horas que a pesar de sus limitaciones se pudo inferir que los escolares con déficit de vitamina B12 y ferritina tienen un bajo consumo en productos de origen animal, cereales, leche y un mayor consumo de carbohidratos frutas y vegetales.

Un estudio en Venezuela, menciona que pareciera que existiera una tendencia hacia el aumento de prevalencia de anemia a medida que desciende el nivel socioeconómico ya que ellos aducen que el origen es de tipo nutricional, o puede estar influenciada por factores culturales como ser el tipo de dietas que predomina en el país por ejemplo existen estudios sobre dietas en América Latina que reportan una mayor prevalencia de alimentos inhibidores de la absorción de hierro en el consumo diario con una menor cantidad de facilitadores de la absorción de dicho elemento, como el estudio no es concluyente del síndrome de la pluricarencialidad como ser nivel socioeconómico bajo, anemia, desnutrición, dietas pobres 0 deficiencia especifica de algún nutriente, debe ser motivo para la realización de mayores estudios ${ }^{20,21}$. Así, el déficit de ferritina y de vitamina B12 en la población escolar estudiada nos muestran que se deben dar las bases para que se tomen decisiones políticas nutricionales orientadas a proteger a los grupos de riesgo tales 
como la población de escasos recursos económicos que integran los estratos más bajos de la población. Por años se ha considerado como la anemia mas prevalente es por déficit de hierro, y que las anemias por deficiencia de ácido fólico y vitamina B12 solo se presenta en pacientes muy especiales con alguna enfermedad, sin embargo estos resultados muestran que la deficiencia de ácido fólico se ha ido erradicando mientras que la deficiencia de vitamina B12 es un problema de relativa frecuencia en donde hay que tomar medidas correctivas por las implicaciones que tiene especialmente a nivel de sistema nervioso, estudios han demostrado una asociación entre niveles bajos de vitamina B12 con puntajes disminuidos en inteligencia fluida, habilidad espacial y memoria a corto plazo ${ }^{22}$.

Los resultados de esta investigación se prestan para la toma de decisiones a nivel gubernamental a través de políticas nutricionales certeras dando solución para erradicar problemas nutricionales que son completamente prevenibles y solventables.

\section{AGRADECIMIENTOS}

Las autoras quieren agradecer a todos los maestros de las escuelas participantes, a los escolares y a los padres de familia por su apoyo en la realización de este estudio. Los héroes anónimos.

Ala Dra. En Microbiología Carmen, por su colaboración incondicional.

A la DICU-UNAH, por su valioso soporte económico que sin él no hubiera sido posible este estudio.

Al personal administrativo de la carrera de Microbiología por su meritoria colaboración.

\section{BIBLIOGRAFÍA}

1. United Nations children's fund. The estate of Word's children. New York: UNICEF; 1998

2. Pérez V, Hertrampf E y Olivares M. Folato y Vitamina B12 en Pediatría: Mirada actual. Rev. Ped. Elec. [en línea] 2005; 2: 44-61.

3. Cunningham L., Blanco A, Rodríguez S, Ascencio M. Prevalencia de anemia, deficiencia de hierro y folatos en niños menores de siete años. Costa Rica 1996. Arch Latinoamer Nutr 2001; 51:37-43

4. Rogers L., Boy E., Millar J., Green R., Sabel J. and Allen L. High prevalence of 
cobalamin deficiency in Guatemalan schoolchildren: association with low plasma holotranscobalamin II and elevated serum methylmalonic acid and plasma homocysteine concentrations. Am J Clin Nutr 2003; 77: 433-440.

5. Graham S, Arvela O, Wise G. Long-term neurologic consequences of nutritional vitamin B12 deficiency in infants. J Pediatr. 1992; Nov 121(5 Pt 1): 710-4.

6. Lowman M, Van Dusseldorp M, Van de Vijver F. et al. Signs of impaired cognitive function in adolescents with marginal cobalamin status. Am J Clin Nutr 2000; 72 : 762-769

7. Rivera MF, Soto RJ. Anemia en Población Escolar: Prevalencia y algunos Factores Epidemiológicos Asociados. Rev Med Hondur 1999; 67:135-140.

8. Nestel P, Melara A, Rosado J, Mora JO. Vitamin a deficiency and anemia among children 12-71 months old in Honduras, Rev Panam Salud Publica 1999; 6 (1) July .

9. World Health Organization guidelines for food fortification with micronutrients. Geneva Switerzerland: world Organization. Department of nutrition for health and development, 2006

10. Assessing iron status of populations, second Edition. ISBN 9789241596107 (electronic version),

11. Conclusions of a WHO Technical Consultation on folate and vitamin B12 deficiencies. Food and Nutrition Bulletin: 2008; 29 (supplement), S238-S246.

12. Alvarez M de la L, Muzzo S, Ivanivic D. Escala de medición del nivel socioeconómico en el área de la salud. Rev Med Chile, 1985; 113:243-249.

13. Parrillon C, Valverde V., Delgado H. \& Newman B. Distribución político administrativa del Estado Nutricional según el Censo de Niños Escolares del Primer Grado en Panamá. Arch Latin Nutrición, 1988; 38: $42-54$

14. Quizhpe E, San Sebastian M, Hurting AK, Llamas A. Prevalencia de anemia en escolares de la zona amazónica del Ecuador. Rev Panam Salud Publica 2003; 13(6): 355-361

15. Allen L, Rosado J, Martinez H, López P, Munoz E. and Black A. vitamin B12 deficiency and malabsortion are highly prevalent in rural mexican communities. Am J Clin Nutr 1995 Nov; 62(5): 1013-1019

16. Rogers L, Boy E, Millar J, Green R, Sabel J and Allen L. High prevalence de cobalamina deficiency in Guatemala a schoolchildren association with low plasma holotranscobalamin II and elevated serum methylmalonic acid and plasma homocystreine concentrations. Am J Clin Nutr 2003; 77: 433-440

17. Olivares M, Anderson M, Llaguno S, Cayazzo M, Steckel A. Nutrición de folato en escolares. Rev Chilena de Pediatría 1985; 56(3): 157-159.

18. Garcia M. Situación de ácido fólico, vitamina B12 en niños, adolescentes y mujeres embarazadas de Venezuela. IVIC-FUNDACREDESA-INN. (Instituto venezolano de investigaciones científicas, Caracas, diciembre del 2003. 
19. Chandra J, Jain V, Narayan $S$, et al. Folate and cobalamin deficiency in megaloblastic anemia in children. Indian Pediatric 2002; 39:453-457

20. Acosta A, Amai M, Com BS et al,. Iron Absorption from typical Latin American diets. Am J Clin Nutr 1984; 39:953-962

21. Vásquez de Martínez N, Briacchi B, Sánchez L. Despistaje de anemia en habitantes del área metropolitana de Caracas por el sistema HemoCue.Anales Venezolanos de Nutrición 2007: 20(2); 71-75

22. Lowman M, Van Dusseldorp M, Van de Vijver F, et al. Sings de impaired cognitive function in adolescents with marginal cobalamin status. Am J Clin Nutr 2000; 72: 762-767 